\title{
Study of role of tablet misoprostol and extra amniotic normal saline in second trimester abortion
}

\author{
Zinkal P. Kothadiya*, Bhavesh B. Airao, Bipin R. Shah
}

Department of Obstetrics and Gynecology, C. U. Shah Medical College and Hospital, Surendranagar, Gujarat, India

Received: 25 October 2018

Accepted: 28 November 2018

\section{*Correspondence:}

Dr. Zinkal P. Kothadiya,

E-mail: zinkalkothadiya@gmail.com

Copyright: (C) the author(s), publisher and licensee Medip Academy. This is an open-access article distributed under the terms of the Creative Commons Attribution Non-Commercial License, which permits unrestricted non-commercial use, distribution, and reproduction in any medium, provided the original work is properly cited.

\begin{abstract}
Background: Second-trimester pregnancy termination comprises 10 to 15 percent of the approximately 42 million abortions performed annually worldwide. Second-trimester procedures can be performed either with medication or by mechanical methods (Foleys catheter) or surgically by dilation and evacuation (D and E) or hysterotomy. The objective of the present study was to evaluate and compare the efficacy and safety of Tablet Misoprostol and extra amniotic infusion of normal saline with balloon catheter in second trimester abortion, to find out the maternal outcome, to compare the induction- to delivery interval between tablet misoprostol and extra amniotic infusion of normal saline with balloon catheter and to compare the cost of induction between tablet misoprostol and extra amniotic infusion of normal saline with balloon catheter.

Methods: This randomized controlled study was carried out in the Obstetrics and Gynecology. Department of C.U. Shah Medical College, Surendranagar, from 23th August 2017 to 20th August 2018.

Results: Amongst the 100 participants, 50 induction is done with tab. Misoprostol and 50 induction done with EASIBC. Success rate is higher in tab. Misoprost which is $90.20 \%$ and in EASIBC is $75.51 \%$. There were longer induction abortion interval in EASIBC: Need for curettage among Misoprostol is 5 and EASIBC is 9. Major complication like PPH occurred in two cases in induction with tab. Misoprostol, which is managed by further intervention and no death occurred. No major complication occurred in induction with EASIBC.

Conclusions: Excluding the side effects and complications, which are manageable induction with tab. Misoprostol is better than EASIBC in terms of induction abortion interval, effectiveness, acceptability.
\end{abstract}

Keywords: Extra amniotic infusion of normal saline, Second trimester abortion, Tablet Misoprostol

\section{INTRODUCTION}

Despite the recent advances in prenatal diagnosis in first trimester, termination of pregnancy in second trimester due to fetal abnormalities and intrauterine fetal death still accounts for large number of abortions and has increased the demand for rapid termination of pregnancy. Secondtrimester pregnancy termination comprises 10 to 15 percent of the approximately 42 million abortions performed annually worldwide. ${ }^{1}$ Second-trimester procedures can be performed either with medication or by mechanical methods (Foleys catheter) or surgically by dilation and evacuation (D and E) or hysterotomy.
Worldwide, one third or even half of all pregnancies are estimated to be unintended, and every fifth pregnancy ends in an induced abortion. ${ }^{1}$ The Medical Termination of Pregnancy Act was passed in 1972 in India. Since then a large number of women have availed the facility of safe abortion in government and private hospitals. (2) While massive national and worldwide initiatives are being taken to reduce morbidity and mortality from unsafe abortion, the fact remains that abortion is an important cause of maternal mortality.

There are various methods in 2nd trimester abortion which are as following: 


\section{Medical}

- Prostaglandins

- I/M carboprost.

- Vaginal passery.

- Oral-mifepristone + misoprostol.

- Extra amniotic injections (intrauterine transvaginally)

- Ethacridine lactate, normal saline.

- Intra amniotic injections (Trans abdominal).

- Hypertonic solutions (20\% saline): not used now a days.

- Others: prostaglandins and even ethacridine lactate can also be used by intra amniotic route.

\section{Surgical}

- Aspirotomy.

- Hysterotomy. ${ }^{3}$

Extra amniotic installation of Ethacridine Lactate has been the tradional method for termination of pregnancy in India for more than three decades. While the procedure is notable for its safety, its efficacy is far from satisfactory with high failure rates, long induction-abortion intervals and complications. ${ }^{4}$

The Prostaglandins from the E group have a higher ratio of cervical ripening to uterine contractility and are preferred to Prostaglandins of the F group. Among these Misoprostol is a Prostaglandin E1 Analogue that has recently been used by a number of authors for second trimester abortions singly or with Mifepristone RU 486, Methotrexate, Gemeprost, Ethacridine lactate. Misoprostol is being (off label) used for termination of pregnancy in between 13 and 20 weeks, in different doses and by different routes with better results. ${ }^{5}$

\section{METHODS}

This randomized controlled study was carried out in the obs. And gynec. Department of C.U. Shah Medical College, Surendranagar, from 22th December 2015 to 20th October 2017. Pregnant women needing termination between 12 to 20 weeks were enrolled.

The cases were randomized into two groups:

- Group A: tab. misoprostol

- Group B: extra amniotic saline infusion with balloon catheter. (EASIBC)

Pregnant ladies attending the OPD of obs. And gynec. Department of CUSMCH, Surendranagar for II trimester MTP who fulfil inclusion and exclusion criteria were selected for the study. Ultrasound examination was used for the date confirmation and their eligibility to enter into the study. Selected patients were admitted to obstetrics ward and procedure will be planned. Complete evaluation of each patient was done at admission. Detailed history as well as clinical findings of medical and obstetric examination was recorded. Informed consent was taken, thorough detailed counselling the patient about the different procedures and methods for the termination were done.

Patients were assigned into 2 groups on admission.

In group $\mathrm{A}$, randomly selected 50 cases, Induction was carried out using Intravaginal Misoprostol 400 microgram, and repeated every six hours with dose of 200 microgram, up to a maximum duration of 72 hours. In present study if no expulsion occurred within 72-hour failure would be considered.

In group B, randomly selected 50 cases, Induction was done by extra amniotic saline infusion with balloon catheter. Here, French's Foley's catheter no. 16 is used as a balloon catheter, as easily available and widely used When catheter expelled out spontaneously then catheter was checked for any defect and per vaginal examination was done to assess cervical dilatation and effacement. If no expulsion of catheter within 72-hour failure would be considered.

\section{Inclusion criteria}

- Pregnancy between 12-20 weeks of gestational age with no known hypersensitivity to prostaglandins.

- IUFD

- Fetus With congenital anomaly

- Maternal factor: Continuation of pregnancy constitutes risk to the life or grave injury to the physical or mental health of woman

- Pregnancy due to failure of contraception

- Pregnancy caused by rape (presumed grave injury to mental health)

- Ruptured membrane.

\section{Exclusion criteria}

- In process of abortion

- Cervical incompetence

- Hypersensitivity to prostaglandins

- More than one previous caesarean section

- Previous major uterine surgery

- Medical conditions like impaired cardiac, renal and hepatic function

- Pelvic inflammatory diseases

- Severe anemia, coagulopath

- Large size uterine fibroid

- Cervical malignancy

- Uncontrolled diabetes

- Severe uncontrolled hypertension

- Placenta previa.

To evaluate the success of the cervical ripening, the primary outcome, measures which are taken is following: 
- Dilatation and effacement

The mode of the delivery

- Normal evacuation

- Dilatation and evacuation

- Hysterotomy.

By Trans vaginal sonography, check weather complete expulsion (fetus with placenta) or incomplete expulsion. If the expulsion is incomplete, then remaining product is removed by check and curettage.

Induction-abortion interval

- The induction-to-abortion interval was defined as the time from the first induction to fetal expulsion.

All patients were closely monitored for hyper stimulation, tachysystole. Induction was considered successful if women aborted within 72 hours. If induction failed, then either dilatation and evacuation or hysterotomy were taken.

\section{Statistical analysis}

At the end of study relevant information was analyzed by making different tables and graphical forms and statistical analysis techniques i.e. ' $Z$ ' test for qualitative data and 'Chi square test' will be applied by determining the probability that is ' $p$ ' value with the help of faculty members from the department of biostatistics.

\section{RESULTS}

In present study number of participants are 100. Among them more than $50 \%$ are between age group of 21-30 years and $28 \%$ alone in age group between 21-24 years.
There were $50 \%$ primigravidas and $50 \%$ multigravidas. The most common indication in this study is fetal indication. In fetal indication most common indication is congenital malformation $41 \%$ and second most common is IUFD 29\%. Amongst the 100 participants, 50 induction is done with tab. Misoprostol and 50 induction done with EASIBC. the dose of the tab. Misoprost needed for the abortion is higher in primigravida (average $1114 \mathrm{mcg}$ ) than multigravida $(826 \mathrm{mcg})$.

There were less number of inductions required in multigravida. the success rate of two methods. Highest in tab. Misoprost which is $90.20 \%$ and in EASIBC is $75.51 \%$.

There were longer induction abortion interval in EASIBC ( $\sim 33$ hour) than Miso ( $\sim 15$ hour) In tab. Misoprostol 45 patients aborted with normal evacuation and in EASIBC 36 patients. While need for dilatation and evacuation is in 4 patients in whom induction done with tab. Misoprost and in 8 patients with EASIBC. In group A There were total 6 patients, in which further curettage was done and in group B there were total 8 .

Table 1: Success rate of Misoprostol and EASIBC.

\begin{tabular}{|l|l|l|l|l|}
\hline $\begin{array}{l}\text { Mode of } \\
\text { induction }\end{array}$ & Patient & Success & Failure & $\begin{array}{l}\text { Success } \\
\text { rate }\end{array}$ \\
\hline Misoprost & 50 & 45 & 5 & $90 \%$ \\
\hline EASIBC & 50 & 36 & 14 & $72 \%$ \\
\hline Total & 100 & 81 & 19 & $81 \%$ \\
\hline
\end{tabular}

Major complication like PPH occurred in two cases in induction with tab. Misoprostol, which is managed by further intervention and no death occurred. No major complication occurred in induction with EASIBC. Most of the minor complication occurred in induction with tab. Misoprost. The most common side effect occurred in my study is diarrhoea.

Table 2: Minor complication.

\begin{tabular}{|l|l|l|l|l|l|l|}
\hline Mode of induction & Cervical tear & Chills and rigor & Diarrhoea & Nausea & Pyrexia & Total \\
\hline Misoprost & $02(10.53 \%)$ & $05(26.32 \%)$ & $06(31.58 \%)$ & $02(10.53 \%)$ & $04(21.05 \%)$ & $19(100 \%)$ \\
\hline EASIBC & $01(12.5 \%)$ & $01(12.5 \%)$ & $01(12.5 \%)$ & $02(25 \%)$ & $03(37.5)$ & $08(100 \%)$ \\
\hline Total & $03(11.11 \%)$ & $06(22.22 \%)$ & $07(25.93 \%)$ & $04(14.81 \%)$ & $07(25.93 \%)$ & $27(100 \%)$ \\
\hline
\end{tabular}

\section{DISCUSSION}

The study conducted by Suryaprakash Jagdevappa Karande, Meena Shantanu Gunjotikar conclude that, as compared to extra-amniotic instillation of normal saline, intravaginal misoprostol is the preferred regimen in second trimester abortion because of its high efficacy, shorter induction abortion interval, high incidence of completeness of abortion and better tolerance by the patient. ${ }^{6}$ The study conducted by Patrick M. Mullin, MPH, Michael House, MD, Richard H. Paul, Deborah A. Wing, concluded that Extra amniotic saline solution infusion with balloon's catheter administration appears more effective and associated with fewer maternal complications than misoprostol for induction of labour in second trimester. ${ }^{7}$ The study conducted by A. Amirabi found that in 2 nd trimester abortion by tab. Misoprostol 
have more side effects than EASIBC but failure rate is more in EASIBC with more chance of retained products and post abortal bleeding. ${ }^{8}$ The study conducted by Asma Shaheen, Raazia Rauf, Attiqa Zaigham, Fareesa Waqar concluded that misoprostol is better than EASIBC for second trimester abortion in terms of efficacy, patient's compliance, induction-abortion interval and completeness of the abortion. ${ }^{9}$ The results of the study gives slightly higher edge to misoprostol comparison with extra amniotic saline infusion with balloon catheter in contrast to convenience of the procedure, induction abortion interval, rate of complete abortion. As in EASIBC, the PGs are produced in vivo by stripping of the membrane and activation of proctoclytic enzyme in the decidua on the other hand tab. Misoprostol is itself a PGE1 derivative and directly provides prostaglandin to the tissues. $^{10,11}$ Results of this study itself indicates misoprostol has less induction abortion interval as compare to extra amniotic saline infusion with balloon catheter. This can be explained by that in EASIBC the prostaglandins are naturally produced in the body and when its concentration reached the process of abortion is start, while in tab. Misoprostol already preformed prostaglandins are introduced inside the body, so starting of the process of abortion is earlier. ${ }^{7}$

\section{CONCLUSION}

In present study we compare the two groups: group A and group B, which contains tab. Misoprostol and EASIBC. This study shows induction abortion interval is shorter in induction with tab. Misoprostol as compare to induction by EASIBC. In both group of studies, induction abortion interval decreases and success rate is increases with parity.In terms of side effects and complications, EASIBC group having less complications and side effects compare to misoprostol. There is no cost wise significant difference between the both groups. Since failure rate and need for the further intervention like $D$ and $E$, hysterotomy, misoprostol is superior than EASIBC. Induction by EASIBC needed further procedure like Check and curettage after normal evacuation as compare to tab. Misoprostol. Induction with tab. Misoprostol can't be done in a patient with medical disorder like heart disease, coagulation disorder, where induction with EASIBC is safe. Excluding the side effects and complications, which are manageable induction with tab. Misoprostol is better than EASIBC in terms of induction abortion interval, effectiveness, acceptability.

Funding: No funding sources

Conflict of interest: None declared

Ethical approval: The study was approved by the Institutional Ethics Committee

\section{REFERENCES}

1. Barbara Hoffman, Scott Roberts, Robyn Horsager, Vanessa Rogers, Patricia Santiago-Muñoz, Kevin
Worley Williams Obstetrics, 24th Edition, Study Guide; McGraw Hill Education, pp no 250

2. Ministry of health and family welfare of India. Available at https://mohfw.gov.in/acts-rules-andstandards-health-sector

3. Barbara Hoffman, Scott Roberts, Robyn Horsager, Vanessa Rogers, Patricia Santiago-Muñoz, Kevin Worley Williams Obstetrics, 24th Edition, Study Guide; McGraw Hill Education, pp no 369

4. Laul RM, Mahale AR, Bhattacharya PR. Termination of mid trimester pregnancies with extraamniotic $0.1 \%$ ethacridine lactate. Accurate method for estimation of blood loss. Role of spartein sulfate. Asia Oceania J Obstet Gynaecol. 1984;10(2):185-9.

5. Kulier R, Kapp N, Gülmezoglu AM, Hofmeyr GJ, Cheng L, Campana A. Medical methods for first trimester abortion. The Cochrane Library. 2011.

6. Karande SJ, Gunjotikar MS, Comparative study between intravaginal misoprostol and extraamniotic instillation of ethacridine lactacte for second trimester abortion Int J Reprod Contracept Obstet Gynecol. 2017;6(6):2575-9.

7. Mullin PM, House M, Paul RH, Wing DA, A comparison of vaginally administered misoprostol with extra-amniotic saline solution infusion for cervical ripening and labor induction. AJOG. 2002;187(4):847-52

8. Amirabi A, Golmohammadlou S, Lak SS, Khabiry L A comparative study of extra - amniotic saline infusion and high dose oxytocin with prostaglandin e2 suppository and high dose oxytocin in pre induction cervical ripening in second trimester pregnancies. J Urmia Univ Med Sci. 2009,19(4): 295-301.

9. Shaheen S, Rauf R, Zaigham A, Waqar F. A Comparison of Oral Misoprostol and Extra-amniotic Foley's Catheter with Oxytocin for Induction of Labour at Term.

10. Vengalil SR, Guinn DA, Olabi NF, Burd LI, Owen J. A randomized trial of misoprostol and extra-amniotic saline infusion for cervical ripening and labor induction. Obstet Gynecol. 1998;91(5):774-9.

11. Adeniji OA, Oladokun A, Olayemi O, Adeniji OI, Odukogbe AA, Ogunbode O, et al. Pre-induction cervical ripening: transcervical foley catheter versus intravaginal misoprostol. J Obstet Gynaecol. 2005;25(2):134-9.

Cite this article as: Kothadiya ZP, Airao BA, Shah BR. Study of role of tablet misoprostol and extra amniotic normal saline in second trimester abortion. Int J Reprod Contracept Obstet Gynecol 2019;8:2347. 